\title{
INTERFERÊNCIAS E INFLUÊNCIAS ANTRÓPICAS NA BACIA DO RIBEIRÃO JACUBA, A PARTIR DO PROCESSO DE URBANIZAÇÃO DO MUNICÍPIO DE HORTOLÂNDIA-SP
}

\author{
Alexandre Lippaus Rocha ${ }^{(a)}$, Archimedes Perez Filho $^{(b)}$ \\ (a) Instituto de Geociências, Universidade Estadual de Campinas, alexandre.lippaus@ gmail.com \\ (b) Departamento de Geografia, Universidade Estadual de Campinas, archi@ige.unicamp.br
}

Eixo: Uso e ocupação das terras e legislação ambiental

\begin{abstract}
Resumo
Modificações nas morfologias de rede de drenagem da bacia do ribeirão Jacuba, são reflexos dos agentes modeladores de relevo, bem como, da interação entre as atividades antrópicas e os fatores físicos da paisagem, atuando no decorrer do processo de urbanização do município de Hortolândia/SP. Realizou-se levantamento das características do uso e ocupação das terras de períodos entre 1962 e 2010, visando entender dinâmicas de atividades antrópicas sobre tal território, correlacionando-as com alterações da atual rede drenagem. Foram utilizadas cartas topográficas, imagens orbitais e imagens aéreas da região em diversos períodos, assim como, documentos cedidos pela prefeitura de Hortolândia, nos quais representaram o crescimento urbano do município, no qual se insere a bacia hidrográfica o rio Jacuba. Verificou-se desaparecimento de rios de primeira ordem, diminuição da área da planície de inundação e retificação do Ribeirão Jacuba. Simultaneamente, houve avanço do processo de urbanização, pressionando suas margens.
\end{abstract}

Palavras chave: Geomorfologia Antropogênica. Ribeirão Jacuba. Uso e Ocupação das Terras.

\section{Introdução}

O córrego Jacuba, principal canal fluvial da bacia, localizada no município de Hortolândia/SP, teve significativa importância na história da cidade. Tropeiros o utilizavam para pouso, banho, pesca, e comer um pirão denominado de "Jacuba", constituído de farinha de mandioca, cachaça, açúcar e mel, batizando o vilarejo local com este nome. Este, por sua vez, mudou de nome em 1954, passando a se chamar Hortolândia. A área de estudo se localiza na Depressão Periférica Paulista, abrangendo 62,416 km², constituída por relevo levemente ondulado. Município da Região Metropolitana de Campinas (RMC), Hortolândia possuia 192.692 habitantes em 2010, sendo estimado 212.527 habitantes para 2014, perfazendo elevada densidade demográfica de 3094,22 habitantes $/ \mathrm{km}^{2}$ (IBGE, CENSO 2010). O censo de 2000, realizado pelo IBGE, considerou Hortolândia como o décimo município que mais cresce populacionalmente no estado de São Paulo, baseando-se na "taxa média geométrica de crescimento anual", equivalente a 6,59\%. Em 2010, a prefeitura do município publicou a seguinte frase: "Hortolândia, a cidade próspera que mais cresce no Brasil” (POLIDORO, 2013). Tal expansão urbana teve início na 
década de 1970, com migração de setores industriais e tecnológicos, da Região Metropolitana de São Paulo (RMSP), para a RMC. Hortolândia, portanto, sofreu súbito crescimento demográfico, impulsionada pela Industrialização pós década de 70, focada no setor tecnológico (POLIDORO, 2013).

Tal aumento populacional tem como consequência a construção de estruturas urbanas, responsáveis pela impermeabilização do solo, aterro nas áreas de planície de inundação, modificação nas formas de relevo e retirada dos materiais litológicos, influenciando em uma nova dinâmica modeladora do relevo (LUZ, 2014). O presente trabalho visa identificar e analisar as transformações relativas ao uso e ocupação das terras ocorridas no município de Hortolândia, nos últimos 50 anos, baseando-se em seu processo de expansão urbana, enfatizando nas modificações no comportamento do canal fluvial principal e de sua correspondente planície de inundação.

\section{Metodologia}

Considerou-se bacias hidrográficas, assim como planícies de inundações, sistemas abertos, ocorrendo entrada e saída de matéria e energia, proveniente da interação de formas e processos entre o geossistema. Este, por sua vez, representa a interação dialética entre o clima, vegetação, solo e relevo, com as ações antrópicas atuando como "inputs" ao sistema, isto é, potencializadoras das formas e processos encontrados nos geossistemas. Tal conceito, é o mesmo trabalhado por BRIGUENTI (2005), baseando-se em CHRISTOFOLETTI (1999), em que "o geossistema representa a organização espacial resultante da interação dos elementos componentes físicos da natureza. (...) Christofoletti ressalta que os elementos humanos (sistema sócio-econômico) devem ser entendidos e estudados como "inputs" que interagem na estrutura do geossistema, mas não fazem parte do seu sistema funcional” (BRIGUENTI, 2005).

Para que tal estudo fosse realizado, foi necessário a restituição da rede de drenagem da bacia do Ribeirão Jacuba, sendo realizado a vetorização da drenagem, baseando-se em cartas topográficas 1:10.000 do Instituto Geográfico e Cartográfico do estado de São Paulo, primeira edição em 1979 e com restituição de 2002, totalizando 6 cartas (IGC, 2002) as quais foram georreferenciadas por meio do software ArcGIS 10.1, bem como, três mapas referentes a zona urbana do município de Hortolândia, baseando-se no mapa da "Evolução histórica de Hortolândia", cedido pela prefeitura, contendo informações de espaços já urbanizados em 1993, 2005 e, em processo de urbanização, em 2009.

Para mapeamento do uso e ocupação das terras, foram utilizadas imagens aéreas, de escala aproximada 1:25.000, disponibilizados pelo Instituto Agronômico de Campinas (IAC), referem-se aos anos de 1962, totalizando 17 fotografias utilizadas, formando 10 estereopares, e de 1972, com 21 fotografias utilizadas, sendo formados 15 esteropares. Tais fotografias, foram sobrepostas no Software StereoPhoto Maker. Para 
o mapeamento referente ao ano de 2010, de escala aproximada de 1:10.000, foi utilizada imagem aérea, cedida pela prefeitura. As imagens geradas ou sobrepostas, foram introduzidas no ArcGIS, georreferenciadas com base nas cartas topográficas.

Foi realizado levantamento bibliográfico, focando-se em temas que envolvem Geomorfologia Histórica e Geomorfologia Antrópica, afim de contribuir para arcabouço teórico quanto ao uso e ocupação das terras nas características gerais da rede de drenagem, que tem como canal principal o Ribeirão Jacuba. Procurouse entender a metodologia utilizada pelos autores LUZ (2014) e Briguenti (2005).

Para tal mapeamento, foram definidas as seguintes classes, a partir de IBGE (2013), "Pastagem"; "Silvicultura"; "Área agrícola"; "Área de mata"; "Solo Exposto"; "Mineração"; "Planície de Inundação do Ribeirão Jacuba"; “Área susceptível a inundação"; "Urbanizado"; "Em Urbanização”; "Uso não identificado", sendo classificadas manualmente, a partir das imagens aéreas, sob auxílio do software ArcGIS e de MARCHETTI (1982). Cada uma das classes representa comportamentos de escoamento pluvial superficial, infiltração, remoção, transporte e deposição de materiais distintos, sendo tais mapeamentos, úteis não somente para entendimento da dinâmica fluvial, sob influência antrópica, como também, para estudos ambientais e planejamento urbano.

\section{Resultados e discussão}

Foram identificados 79 canais de primeira ordem no território municipal de Hortolândia. A partir dos mapas de área urbana, de 1993, 2005 e 2009, realizados com base em dados da prefeitura municipal de Hortolândia, foi identificado que, as delimitações de áreas consideradas urbanas, expandiu sobre 16 canais de primeira ordem em 1993; 32 em 2005 e 43 em 2009. No ano de 1993, 19,188\% do município era urbanizado, em 2005 o número passou para 44,387\%, totalizando 27,705 km² do município. Em 2009, $52,175 \%$ da área do município já estava urbanizada ou em processo de urbanização.

Quanto ao mapeamento de uso e ocupação das terras, em 1962, compreendiam extensas áreas destinadas a pastagem, associadas a silvicultura. Áreas de mata nativa localizavam-se ao longo dos cursos fluviais e em porções de terras altas. Não foi identificado processos de urbanização nos canais de primeira ordem. A área urbana localizava-se na atual região de centro comercial de Hortolândia, próximo ao Ribeirão Jacuba. Em 1972, predominam áreas de pastagem frente à silvicultura. Percebe-se avanço de áreas destinadas a agricultura perene e temporária, principalmente sobre o oeste do município. O número de estruturas urbanas aumenta, assim como, a área em urbanização, sendo identificado loteamentos ao sul. A área de mata continua acompanhando a rede de drenagem em alguns pontos, ocorrendo, também, aleatoriamente entre áreas destinadas a pastagem. Já 2010 corresponde a uma paisagem densamente urbanizada, 
avançando em áreas da planície de inundação no alto e médio curso. À oeste do município, encontra-se aglomeração de uso agrícola, predominando cana de açúcar e mandioca. Identificou-se processo de retificação do Ribeirão Jacuba, em seu médio curso inferior, havendo adensamentos urbanos sobre canais de primeira ordem. A seguir, na Tabela I, está presente dados retirados de tais mapeamentos, referentes à área das seguintes classes: Pastagem; Mineração; Uso Agrícola; Área de Mata; Silvicultura; Área Urbana e Área em Urbanização.

Tabela I. Percentual de tamanho dimensional de determinados usos, em relação a área do município de Hortolândia/SP. Fonte: "Evolução Histórica da Urbanização". Prefeitura de Hortolândia, para os anos de 1993; 2005 e 2009**; Imagens não orbitais e fotointerpretação para os anos de 1962; 1972 e 2010. (*Por S/D entende-se "Sem dados").

\begin{tabular}{ccccccc}
\hline Uso & Área 1962 & Área 1972 & Área 2010 & & & \\
\hline Pastagem & $43,37 \%$ & $56,75 \%$ & $24,75 \%$ & & & \\
Mineração & $0,17 \%$ & $0,17 \%$ & $0,8 \%$ & & & \\
Uso Agrícola & $2,7 \%$ & $5,9 \%$ & $15,29 \%$ & & & \\
Área de Mata & $4,05 \%$ & $3,69 \%$ & $3,48 \%$ & & & \\
Silvicultura & $38,8 \%$ & $14,9 \%$ & 0 & & & \\
Uso & Área 1962 & Área 1972 & Área 1993 & Área 2005 & Área 2009 & Área 2010 \\
Área urbana & $0,62 \%$ & $0,87 \%$ & $19,18 \% * *$ & $44,38 \% * *$ & $48,33 \% * *$ & $48,62 \%$ \\
Área em urbanização & $6,69 \%$ & $6,79 \%$ & S/D* & S/D* & S/D* & $2,92 \%$ \\
\hline
\end{tabular}

Quanto às planícies de inundação do ribeirão Jacuba, foram calculadas as áreas dos anos de 1962 e de 2010. Estando o resultado presente na Tabela II.

Tabela II. Áreas das planícies de inundação do Ribeirão Jacuba, de 1962 e 2010, por trecho do canal fluvial. (Em ha).

\begin{tabular}{cccccc}
\hline Ano & Baixo Curso & Médio Curso Inferior & Médio Curso Superior & Alto Curso & Total \\
\hline 1962 & 71,97 & 25,98 & 37,89 & 43,34 & 79,18 \\
2010 & 60,75 & 14,16 & 21,53 & 20,1 & 116,54 \\
\hline
\end{tabular}

\section{Considerações finais}

O Ribeirão Jacuba, canal fluvial com características típicas de um rio de planície, em 1962, apresentava-se meandrante, serpenteando os vales do atual território de Hortolândia. A área de sua planície de inundação, nesta mesma época, perfazia em 179,18 ha. As estruturas urbanas, nesta época, se concentravam no médio curso inferior do Ribeirão, atual centro comercial do município. A partir de 1972, identificou-se no município três focos de urbanização, no médio curso inferior, expandido para sul, acompanhando o córrego Boa Vista (Afluente do Ribeirão Jacuba), norte e leste, acompanhando o Ribeirão Jacuba; ao sul do município, onde atualmente se localiza o bairro "Jardim Amanda" e a Leste do município, próximo ao 
alto curso, onde atualmente, localizam-se setores industriais. A partir destes focos, Hortolândia foi sofrendo processos de urbanização, pressionando a rede de drenagem. Em 2010, alcançou a marca de $48,62 \%$ do território urbanizado, tendo como características a expansão das estruturas urbanas sobre as planícies de inundação do Ribeirão Jacuba, mais especificamente no Médio Curso Inferior, ao qual, em 2010, tal canal fluvial, neste trecho, encontrava-se em processo de canalização e retificação. A diminuição areal das planícies de inundação, pode ser explicada devido ao avanço das estruturas urbanas sobre a planície de inundação, sendo estas passíveis de inundação em 2010.

Em áreas urbanizadas susceptíveis a inundação, canais fluviais recebem maior fluxo, reflexo da impermeabilização do solo, causado pela expansão urbana. Com a maior taxa de escoamento superficial, tem-se maior energia dos fluxos, sendo capazes de transportar sedimentos de maior dimensão à jusante dos canais fluviais, modificando os processos erosivos, interferindo nos processos morfodinâmicos do local, assim como, potencializando pontos de enchentes à jusante.

\section{Agradecimento}

O primeiro autor agradece ao Conselho Nacional de Pesquisa e Desenvolvimento pela bolsa de iniciação cientifica (PIBIC) concedida.

\section{Bibliografia}

BRIGUENTI, E.C. O Uso de Geoindicadores na Avaliação da Qualidade Ambiental da Bacia do Ribeirão Anhumas, Campinas/SP. Janeiro de 2005. Pp.140. Dissertação de Mestrado. Instituto de Geociências Universidade Estadual de Campinas. 2005.

CHRISTOFOLETTI, A. Modelagem de Sistemas Ambientais. São Paulo: Edgard Blücher, 1999.

IAC. Fotografias Aéreas. 1962. Escala aproximada: 1:25.000.IBGE. Manual Técnico de Uso da Terra. Diretoria de Geociências. Rio de Janeiro, 2013. Pp.171.

IBGE. Manual Técnico de Uso da Terra. Diretoria de Geociências. Rio de Janeiro, 2013. Pp.171.

IGC. Cartas Topográficas 95/74; 95/75; 95/76; 96/74; 96/75; 96/76; 97/74; 97/75; 97/76. 1979; 2002/2003. Escala: $1: 10.000 .2002$.

LUZ, R.A. Mudanças geomorfológicas na planície fluvial do Rio Pinheiros, São Paulo (SP), ao longo do processo de urbanização. 2014. Pp. 245. Tese (Doutorado) - Faculdade de Filosofia, Letras e Ciências Humanas. Universidade de São Paulo. 2014. 
MARCHETTI, D.A.B. Princípios de Fotogrametria e Fotointepretação. Nobel. São Paulo. 1988. pp. 257.POLIDORO, M. Desafios técnicos e institucionais na aplicação de instrumentos inovadores de planejamento e gestão urbanos: o caso de Hortolândia - São Paulo. Revista Terr@ Plural, Ponta Grossa, v.7, n.1, p.92-108, jan/jun 2013. Disponível em: < http://www.revistas2.uepg.br/index.php/tp/article/viewFile/3526/3415 >

POLIDORO, M. Desafios técnicos e institucionais na aplicação de instrumentos inovadores de planejamento e gestão urbanos: o caso de Hortolândia - São Paulo. Revista Terr@Plural, Ponta Grossa, v.7, n.1, p.92-108, jan/jun 2013. Disponível em: < http://www.revistas2.uepg.br/index.php/tp/article/viewFile/3526/3415 > 